\title{
Relevance of Linguistic Typology to Formal Theory: Minimalist Inquiry and Word Order
}

\author{
Jae Jung Song * \\ (University of Otago, New Zealand)
}

\begin{abstract}
This article argues that the theoretical desiderata of Minimalist Program (MP) will actually necessitate, or even force, a high level of sensitivity to cross-linguistic structural variation, at least higher than has been the case in Principles and Parameters Theory. Moreover, this heightened sensitivity to cross-linguistic variation is likely to call into question two fundamental assumptions in Generative Grammar (GG), namely the distinction between competence and performance as well as the objection to the inclusion of performance in linguistic theory. By drawing on word order and, to a lesser extent, case marking (also related ultimately to linearization) for purposes of illustration, the article will explain how GG, as reconfigured in MP, needs Linguistic Typology more than ever, as MP theorists are becoming increasingly aware of the relevance of cross-linguistic variation to their minimalist inquiry. Furthermore, functional motivations or explanations (e.g. performance), typically utilized in LT, are likely to resonate well with the minimalist focus on so-called interface conditions.
\end{abstract}

Keywords: competence, interface conditions, linguistic typology, minimalist program, performance, word order

\section{Introduction}

This article draws its inspiration from Anna Siewierska's 2006 article on the relation between functionalism and formalism. In that insightful article, Siewierska discusses a number of areas where functionalism (e.g. Linguistic Typology) and formalism (e.g. Chomskian Generative Grammar and Optimality Theory) may converge or diverge in their common pursuit of discovering the nature of human language (cf. Polinsky, 2011). Siewierska's overall assessment is positive in that, while these two approaches have

\footnotetext{
* Dr. Jae Jung Song: Professor of Linguistics at the University of Otago, Dunedin, New Zealand. He is the author of Word order (Cambridge, 2012), The Korean language: Structure, use and context (Routledge, 2005), Linguistic typology: morphology and syntax (Longman, 2001) and Causatives and causation: A universal-typological perspective. (Addison Wesley Longman, 1996), and also the editor of The Oxford Handbook of Linguistic Typology (Oxford, 2011). E-mail: jaejung.song@ otago.ac.nz.
} 
differences (e.g. different interpretations of cross-linguistic diversity, implicational universals, etc.), formalists "have drawn on [Linguistic Typology] and used it to help elucidate their own theoretical positions" (Siewierska, 2006:72). Thus Siewierska (2006:72) concludes that "[f]rom the point of view of a typologist, what is the most significant is that [Linguistic Typology] is not being ignored [by formalists]".

As Siewierska (2006:passim) points out, formalists' reliance on Linguistic Typology (hereafter LT) is indeed a significant step away (or forward) from their earlier position, as embodied in Chomsky's (1965:118) remark that “[i]nsofar as attention is restricted to surface structure [as opposed to deep structure], the most that can be expected [from the investigation of the structural diversity in the world's languages] is the discovery of statistical tendencies, such as those proposed by Greenberg (1963)". This dismissive attitude was to fall into disfavor among generative grammarians with the advent in the 1980s of Principles and Parameters (P\&P) Theory, in which what is assumed to be fundamental to language is expressed by inviolable principles whereas what is variable across languages is captured by parameters, with different settings for individual languages. At long last, the tables were turned when Chomsky (1995b:6) wrote:

Within the $\mathrm{P} \& \mathrm{P}$ approach, the problem of typology and language variation arise in somewhat different form than before [e.g. Chomsky (1965)]. Language differences and typology should be reducible to choice of values for parameters. A major problem is to determine just what these options are, and in what components of language they are to be found.

The presence in $\mathrm{P} \& \mathrm{P}$ of parameters is indicative of Chomskian formalists' recognition of cross-linguistic structural variation (Siewierska, 2006:62-67).

Since the birth of Minimalist Program (MP) in the 1990s (Chomsky, 1993), however, various theoretical concepts and assumptions of $\mathrm{P} \& \mathrm{P}$ have been brought under close scrutiny. As its name implies, MP is not a theory as such but a theoretical program within which to evaluate formal theories such as $\mathrm{P} \& \mathrm{P}$ for their worth (for program vs. theory from an MP perspective, see Boeckx, 2006:84-09; also Chomsky, 2000:89-93). Put differently, MP does not supplant P\&P or any theory for that matter, but instead presupposes them for the sake of theoretical evaluation. This kind of evaluation has eventually given rise to the elimination of theoretical concepts such as government, c-command, etc., different levels of representation, i.e. S-Structure (SS), D-Structure (DS), L(ogical) F(orm) and P(honetic) F(orm), and X-bar Theory inter alia. This large-scale elimination, in Siewierska's (2006:67) view, has resulted in "much less structure, fewer derivations and, by the same token, much less room for structural diversity [emphasis added]"; as a consequence, the trend in P\&P towards the recognition of cross-linguistic variation "has in part been reversed in the Minimalist Program" to the extent that that "[...] the reduction of structure within minimalism reduces the scope of linguistic variation, and thus the overall relevance of 
typological diversity for the theory [...]" (Siewierska, 2006:68).

This article continues where Siewierska (2006) left off, as it were, by arguing that the theoretical desiderata of MP will actually necessitate, or even force, a high level of sensitivity to cross-linguistic structural variation, at least higher than has been the case in P\&P. Moreover, this heightened sensitivity to cross-linguistic variation is likely to call into question two fundamental assumptions in Generative Grammar (GG), namely the distinction between competence and performance as well as the objection to the inclusion of performance in linguistic theory. By drawing on word order and, to a lesser extent, case marking (also related ultimately to linearization) for purposes of illustration, the article will explain how GG, as reconfigured in MP, needs LT more than ever, as MP theorists are becoming increasingly aware of the relevance of cross-linguistic variation to their minimalist inquiry. Furthermore, functional motivations or explanations (e.g. performance), typically utilized in LT, are likely to resonate well with the minimalist focus on so-called interface conditions (i.e. instructions legible for the performance systems). Note that Optimality Theory, also included in Siewierska's (2006) discussion, will be left out of the discussion to follow, not because LT has little to offer to it (nothing is further from the truth!), but because there is not much to add to what Siewierska has already said about the relation between LT and Optimality Theory.

The remainder of the article proceeds as follows. Section 2 provides an overview of the major theoretical desiderata of MP, which will serve as a backdrop for the main part of the article. Section 3 describes how word order is dealt with in the context of MP. This section also explains that because of its disposition to discover interface conditions, MP needs typological data, generalizations and explanations much more than previous formal theories did. In particular, the relevance of LT to minimalist inquiry into word order is heightened by MP's need to specify interface conditions that can reconcile a single universal word order with a wide range of surface variants attested in the world's languages. The article comes to a close in Section 4, with a brief conclusion.

\section{Minimalist inquiry: theoretical nature and consequences}

In order to understand why MP demands a high level of sensitivity to cross-linguistic variation, one must first understand what constitutes the minimalist position. There are three dimensions to the minimalist position: (i) virtual conceptual necessity; (ii) economy; and (iii) symmetry (see Song (2012:79-93) for an overview). Virtual conceptual necessity relates to the question of whether or not $\mathrm{X}$ - be it a theoretical assumption or a device of descriptive technology - is indispensable in the light of what we (intuitively) understand or believe to be essential properties of human language. Note that these properties are virtual, not literal, because they are assumed, not proven, to be essential to human language 


\section{Jae Jung Song}

(Chomsky, 1995b:212). For instance, in view of the fact that language is a paring of sound and meaning, there have to be only two types of performance system: articulatoryperceptual (i.e. the sensorimotor system) and conceptual-intentional (i.e. the conceptual systems of thought and action) (Chomsky, 1995b:168-169, 2000:113). If so, there cannot be more than two "interface" levels (i.e. levels of representation). Roughly speaking, the interface level that the sensorimotor system accesses is PF, and the interface level that the systems of thought and action access is LF. What this entails is that the remaining levels of representation in P\&P, i.e. DS and SS, fall outside the purview of virtual conceptual necessity. In his seminal MP article, Chomsky (1993) explores this possibility by asking whether DS and SS can be eliminated without P\&P's empirical coverage being compromised. Chomsky's conclusion is that DS and SS are nothing but non-interface (read: purely theory-internal) levels and that their elimination does not reduce P\&P's empirical coverage. This minimalist thinking leads to the architecture of grammar in:

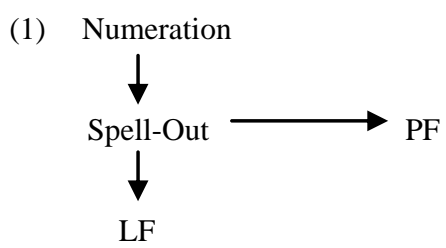

Numeration is a lexical input to the computational operation (Chomsky, 1995b:225). Spell-Out is a computational operation that splits a given computation or derivation into two parts, leading to PF and LF (Chomsky, 1995b:229). Spell-Out is not a level of representation, because no conditions, principles and theories apply at this point.

The two remaining dimensions of the MP position, economy and symmetry, can be illustrated by looking closely at what happens at Spell-Out. While Spell-Out is nothing more than a computational operation, it bears a strong resemblance to SS, because movement operations occur either prior to or after Spell-Out. For instance, in Mandarin Chinese the wh-expression occurs in situ, as opposed to English, in which the wh-expression appears in the sentence-initial position (i.e. displaced from its 'original' position) (e.g. Huang, 1982).

(2) Mandarin Chinese

Xiaolin mai-le shenme?
Xiaolin buy-ASP what
'What did Xiaolin buy?'

To handle this kind of cross-linguistic difference, Chomsky (1995b:232-234) proposes that grammatical features come in two flavors, strong and weak. The wh-feature of the interrogative complementizer in English is strong, while that in Mandarin Chinese is weak. Strong features need to be checked off prior to Spell-Out, while weak features wait until 
after Spell-Out. In English, the wh-expression moves and checks the strong $w h$-feature prior to Spell-Out. Otherwise, the derivation will "crash" or will not "converge" at PF (i.e. *Did Xiaolin buy what?). In Mandarin Chinese, in contrast, the wh-feature is weak and the wh-expression does not need to move prior to Spell-Out, whereby the wh-expression in situ is shipped to PF. Thus pre-Spell-Out movement is equivalent to overt movement, and post-Spell-Out movement to covert movement in P\&P. Chomsky (1995b:261-271) takes this thinking even further by suggesting that the difference between movement prior to Spell-Out and movement after Spell-Out can be reconceptualized as a difference between category movement and feature movement. In the case of weak features, only grammatical features, e.g. the $w h$-feature, are moved. This means that there are no phonological consequences, with their host lexical items or phrases left behind in situ. In the case of strong features, lexical items or phrases in toto must move, because strong features have to be checked off prior to Spell-Out, that is, before derivations are transferred to PF. Otherwise, moved features alone will not be "heard" in the phonetic output (Chomsky, 1995b:265).

This distinction between category and feature movement has implications for economy and symmetry. First, economy in the context of MP means that for language to be an optimal organ, computational resources should not be wasted or purposelessly utilized. When grammatical features are weak, their lexical or phrasal hosts do not need to move along with them, because that would be uneconomical. When grammatical features are strong, however, non-economy considerations must take over and force more than relevant features to be moved so as to achieve PF convergence. To wit, how much (i.e. a category or a feature) is to be moved is dictated by economy considerations. Second, when there is a distinction between pre-Spell-Out and post-Spell-Out movement, the movement operation is asymmetrical: pre-Spell-Out and post-Spell-Out movement operations feed into PF and LF, respectively. With feature movement in place, however, this asymmetry disappears. Now, all movement operations proceed to produce LF objects before being spelled out and in advance of PF. This symmetry makes it possible to revise (1) to:

(3) Numeration $\longrightarrow$ LF $\longrightarrow$ Spell-Out $\longrightarrow$ PF

Minimalist thinking on how to optimize computational resources does not stop here: complete syntactic objects or derivations may not be formed "at one fell swoop" but rather in a piecemeal fashion. Chomsky (2000:106-110, 2001, 2004:107-108) pursues this line of minimalist inquiry by proposing that derivations proceed by "phases". Phases are propositional, or more accurately, $v \mathrm{P}$ and $\mathrm{CP}$ : "verbal phrases with full argument structure [i.e. verb phrases] and CP with force indicators [i.e. clauses]" (also see Chomsky, 2004:122-124). Syntactic objects are assembled in phases and then shipped out to LF and PF on more than one occasion. To wit, Spell-Out occurs not just once but multiple times. 
Thus the interface systems access derivations on multiple occasions and in a dynamic manner (Chomsky, 2000:131, 2001:5). If this is the case, minimalist reasoning continues, why not allow the interface systems to access derivations "without the mediation of LF or PF" (Hornstein, Nunes and Grohmann, 2005:350)? In such a level-free access model, there are the PF and the LF components instead of the PF and the LF levels. The former component converts the derivation directly into interface instructions for the sensorimotor system, and the latter component for the systems of thought and action. Similarly, Uriagereka (1999) proposes what he calls the "Multiple-Spell-Out" model. In this model also, syntactic objects are spelled out as they are assembled, assessing the LF and PF components directly and successively. In these level-free computational models, therefore, "semantic and phonological interpretation need not operate on the output phrase-structure representation (i.e. at a specific level of representation) created by the syntactic derivation [but rather] interpretation is computed derivationally, by interpreting a derivation step by step [emphasis original]" (Boeckx, 2006:76-77). On a more fundamental level, too, this kind of direct, dynamic access to the interface systems will be a welcome development, because if language is an optimal solution to legibility conditions at the interface with performance (Chomsky, 2000:96), research focus should be placed on discovering interface conditions. In this kind of minimalist thinking, therefore, "[i]ssues relating to the interface become of central concern" (Chomsky, 2000:96).

Recent developments in MP have indeed witnessed an increasing amount of emphasis on interface conditions, without resort to the LF and PF levels of representation, that is, converting derivations directly into interface instructions legible to the sensorimotor system and to the systems of thought and action. In Chomsky's (1995b:171) own words, a linguistic expression is now "nothing other than a formal object that satisfies the interface conditions $[\ldots]$ ". This emphasis, in turn, implies that what has previously been relegated to the domain of the interface (i.e. the performance systems or even performance) indeed becomes of central concern. Uriagereka (1999:276) puts it in a more forthright manner:

[Indeed] one consequence [admittedly, unexpected in the tradition of GG, which has always concentrated on competence to the exclusion of performance] is that the gap between competence and performance is partly bridged, radically so in one version of the program [e.g. the Multiple-Spell-Out model]. This has a [serious] repercussion for competence. It provides a rationale for the existence of agreement [between competence and performance] [emphasis added].

What this radical change in theoretical outlook entails is that it is not possible to deny that interface conditions, driven by performance, have a direct, palpable impact upon linguistic expressions themselves. To wit, performance has a place in the scheme of things, as it were.

\section{Word order in MP}


One such thing that has previously been relegated to the domain of the interface system, if not the interface itself, is word order (or linear order, as is usually referred to in GG). Word order is something that has to be sorted out at Spell-Out "because of PF demands" (Uriagereka, 1999:251). There is at least one interface condition that must be met if syntactic objects are going to be ready for manipulation by the sensorimotor system: the "temporal, left-to-right" order or what Boeckx (2008:66) refers to as "the physics of speech". Because of its interface/performance-driven nature (read: surface structure), word order has not been of central concern in pre-minimalist GG. However, once research focus, as in MP, shifts from the theoretically empowered levels of representation (i.e. DS, SS, LF and $\mathrm{PF}$ ) to interface conditions, word order takes on a great deal of theoretical significance. Derivations now have to be converted into specific instructions that the sensorimotor system can read. This means that much attention needs to be paid to the way syntactic objects are linearized prior to being handed over to performance (that is, so that they can be pronounced). But how should hierarchically structured objects (i.e. the Head-Complement relation of $\mathrm{X}$ to $\mathrm{YP}$ and the Specifier-Head relation of $\mathrm{ZP}$ to $\mathrm{X}$ ) be converted directly into linearly ordered objects (e.g. X precedes YP, and ZP, in turn, precedes X) (Uriagereka, 1999:252)? Regardless of how this question is approached, word order has become something that can no longer be taken to be "of secondary interest (if of any interest at all) to [generative] grammarians" (Hornstein, Nunes and Grohmann, 2005:218), as it has previously been.

\subsection{Where is word order in minimalist GG?}

While the centrality of interface conditions is unequivocally recognized in MP, what MP theorists have said about word order may initially seem to suggest something rather different (cf. Siewierska (1988) on word order in pre-minimalist GG; Song (2012:chapter 4) on word order in minimalist GG). For instance, Chomsky (1995a:413; also see Chomsky, 1995b:334) writes that:

ordering [that is, word order] is part of the phonological component, a proposal that has been put forth over the years in various forms. It seems natural to suppose that ordering applies to the output of

Morphology, assigning a linear (temporal, left-to-right) order to the elements it forms, all of them $\mathrm{X}^{\circ} \mathrm{s}$ though not necessarily lexical elements.

Marantz (1995:381) puts it even more bluntly: “[...] word order is phonology [...]". In other words, word order falls outside the language computation proper and is merely something to be imposed on syntactic objects in the phonological component, as the two-dimensional object, i.e. constituent structure with breadth and depth, is forced into a one-dimensional object, i.e. a temporal, left-to-right string of sounds or signs (Hornstein, Nunes and Grohmann, 2005:219, Boeckx, 2008:66). This view on word order has hardly changed as Chomsky (2004:109; also Chomsky, 2005:15) underscores the importance of constituent 


\section{Jae Jung Song}

structure in preference to word order: "[a] fairly standard assumption today, though not in earlier work, is that SEM [= LF object] involves only hierarchy [read: constituent structure], not [word] order [emphasis added]".

Regardless of whether word order is phonology or not, however, serious attention must be paid to linearization, especially in the context of MP. There is a compelling reason for this. In MP, as already explained, heavy emphasis is placed on interface conditions to the effect that linguistic expressions interact with the performance systems more directly than previously (thought) possible. In P\&P, DS and SS are susceptible to different modules or sub-theories of the grammar (e.g. Theta Theory and Case Theory). Linearization should hold off, as it were, until after grammatical operations have been fully implemented at DS or SS. In MP, these operations (e.g. movements) now have to be performed 'on the fly', along with linearization, before syntactic objects are shipped to the interface systems. This means that grammatical operations and linearization have both been rendered susceptible to interface conditions; they have to be dealt with in one and the same place wherever that place may be. Thus "the need to linearize [non-linear, hierarchical phrase markers] upon branching to [the phonological component]" (Uriagereka, 1999:251) becomes paramount. This is perhaps why Chomsky (1995b:334-340) devotes a section to word order while claiming, in the same breath, that there is no clear evidence that word order plays a role in the computation of human language (Chomsky, 1995b:334). Similarly, Hornstein, Nunes and Grohmann (2005), in one of the best (known) introductions to MP, dedicate as much as a whole chapter to linearization, when they, in common with Chomsky (1995b) and Marantz (1995), are of the view that linearization is essentially phonology.

\subsection{Linear Correspondence Axiom: generative theory of linearization}

Within GG, the most influential theory of linearization originates from Kayne's (1994) Linear Correspondence Axiom (LCA) (cf. Chomsky, 1995a; Epstein, Groat, Kawashima and Kitahara, 1998; Hornstein, 2009; and Uriagereka, 1999 for minimalist implementations; also see Song, 2012:141-156). The LCA is designed to convert hierarchical constituent structure into a temporal, left-to-right order. The LCA is based crucially on the structural concept of asymmetric c-command: if $\mathrm{X}$ asymmetrically c-commands $\mathrm{Y}$ (that is, $\mathrm{X}$ c-commands $\mathrm{Y}$ but $\mathrm{Y}$ does not $\mathrm{c}$-command $\mathrm{X}$ ), then the terminal dominated by $\mathrm{X}$ (i.e. $\mathrm{X}$ ) precedes the terminal dominated by $\mathrm{Y}$ (i.e. $\mathrm{y}$ ).

For example, consider a simple phrase marker in (4) (nonterminals in upper case and terminals in lower case). $\mathrm{J}$ asymmetrically c-commands $\mathrm{M}, \mathrm{N}$ and $\mathrm{P}$, while $\mathrm{M}$ asymmetrically c-commands $\mathrm{P}$. Note that $\mathrm{L}$ does not asymmetrically c-command $\mathrm{J}$ (and $\mathrm{N}$ does not asymmetrically c-command $\mathrm{M}$ ). These asymmetric c-command relations can, under the LCA, be translated into precedence relations, namely the ordered pairs of terminals $\langle\mathrm{j}, \mathrm{m}\rangle,\langle\mathrm{j}, \mathrm{p}\rangle$, and $\langle\mathrm{m}, \mathrm{p}\rangle$. These three ordered pairs of terminals, in turn, 
constitute the (required) linear ordering of the set $\{j, m, p\}$, namely $\langle\mathrm{j}, \mathrm{m}, \mathrm{p}\rangle$. Thus asymmetric c-command maps directly onto precedence or linear ordering (Kayne, 1994:33).

(4)

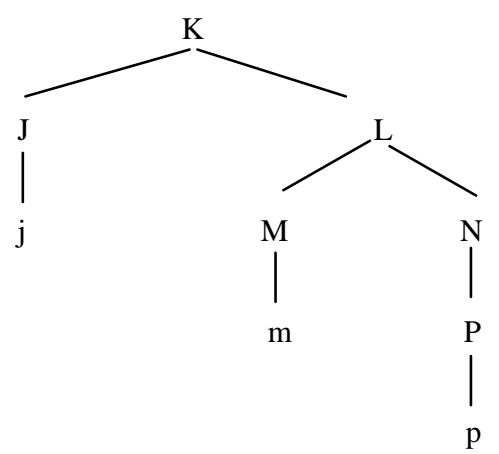

Based on this kind of mapping, Kayne (1994:33-5) proposes that there are only two admissible or possible universal word orders, namely (i) Spec(ifier)-H(ead)-Compl(ement) and (ii) Compl-H-Spec. The reason why only Spec-H-Compl and Compl-H-Spec are admissible is that they alone are sanctioned by the LCA, namely the requirement that 'specifier and complement be on opposite sides of the head" (Kayne, 1994:35). The other four logical possibilities, i.e. Spec-Compl-H, Compl-Spec-H, H-Spec-Compl, and HCompl-Spec, are ruled out because of the violation of the LCA. For example, in SpecCompl-H, the specifier and complement are both on one and the same side of the head (i.e. to the left of $\mathrm{H}$ ); in $\mathrm{H}$-Spec-Compl, the specifier and complement are both to the right of $\mathrm{H}$. This means that in Spec-Compl-H, both Spec and Compl, being nonterminals, are symmetrical with each other. The lack of antisymmetry between Spec and Compl prevents them from being linearized (although they may together be able to be linearized in relation to $\mathrm{H}$ ). The same comment applies mutatis mutandis to $\mathrm{H}-\mathrm{Spec}-\mathrm{Compl}$.

Between the two admissible word orders, i.e. Spec-H-Compl and Compl-H-Spec, Kayne (1994:35-6) opts for Spec-H-Compl. His reasoning is based on empirical grounds. Kayne alludes to the initial positioning of other types of specifiers, e.g. [Spec, CP], which is the typical landing site for moved $w h$-phrases, not to mention the fact that the majority of the world's languages are subject-initial (i.e. Spec-H-Compl) (Greenberg, 1963; Tomlin, 1986 and Dryer, 1992, 2005). In contrast, object-initial languages (i.e. Compl-H-Spec) are known to be considerably less common than subject-initial ones. Thus Kayne (1994:36) comes to the conclusion that the only word order "available to the subcomponents of a phrase" is Spec-H-Compl, not Compl-H-Spec. The universal (abstract) word order is brought into being.

2.3 LCA and cross-linguistic variation

Once the universal word order is decided on, the cross-linguistic variation on word order 
becomes an important issue. The reason could not be more obvious. The disparity between the universal word order and surface word orders, the latter as attested in the world's languages, cannot be ignored or set aside, especially in the context of MP, in which language is claimed to be an optimal solution to legibility conditions at the interface with performance (Chomsky, 2000:96). Otherwise, the status of the universal word order will be open to dispute or very much in doubt. How can different surface word orders be produced from the universal word order? Surface word order variants are claimed to emerge as a direct consequence of movements, e.g. VSO derived from SVO by the leftward movement of $\mathrm{V}$ into INFL. While these movements are language-specific in the sense that what (combinations of) movements should apply depends on individual languages, at least in theory, they do not take place vacuously but in order to satisfy other grammatical requirements - which may have nothing to do with word order (cf. Chomsky, 1995b:28, 256-7). What this means is that some movements may be sanctioned with respect to the universal word order whereas others may not. This difference, in turn, can be exploited, in conjunction with the universal Spec-H-Compl order, to explain why some word-orders are (frequently) attested whereas others are not.

Kayne's LCA theory — or any theory that proposes a universal word order — must work out the 'mechanics' of deriving the complete range of surface word order variants from the underlying Spec-H-Compl order. What is required - or remains to be done - is the mechanics being worked out systematically for each and every phrasal category in order to ascertain whether Kayne's LCA theory can handle the cross-linguistic word order variation (e.g. Dryer, 1992, 2005) - it must be reiterated - both attested and unattested. In view of this obvious need, it comes as a surprise that not much - at least not as much as expected - research has so far been carried out in this particular area. Cinque (1996, 2000, 2005, 2010) - apart from Kayne's $(1994,2000)$ own exploratory work — is a notable exception in that he is virtually the only generative grammarian that has made a serious attempt to reconcile Kayne's LCA theory with the vast amount of typological data available. Cinque's work will be briefly outlined here in order to illustrate how the mechanics of deriving surface variants from the universal word order can be worked out (cf. Steddy and Samek-Lodovici, 2011).

Cinque $(1996,2005)$ sets out to account for the left/right asymmetry observed in the linearization of the various pre-/post-nominal modifiers such as demonstratives (Dem), numerals (Num) and descriptive adjectives (A). Cinque argues that Kayne's LCA theory can deal with this naturally. In common with Kayne (1994), Cinque assumes the universal Spec-H-Compl order, which is to be rearranged by means of movements or combinations of movements. There are 24 logically possible linear orderings of the four elements, Dem, Num, $A$ and $\mathrm{N}(4 \times 3 \times 2 \times 1=24)$. Of these 24 logical permutations, some are attested and 
others unattested in the world's languages (e.g. Greenberg, 1963; Hawkins, 1983). Cinque then demonstrates that while attested ones can be derived from the universal word order by moving (or not moving) the NP or an XP containing it around the modifiers from Spec to Spec, the unattested ones cannot be derived because the universal Spec-H-Compl order is violated regardless of whether the NP or an XP containing it has moved or not. Cinque's (1996:453; 2005:317) somewhat simplified universal structure of the DP involving the nominal modifiers is:

(5) $\quad \ldots\left[{ }_{\mathrm{XP}}\left[{ }_{\mathrm{XP}} \mathrm{X}\left[{ }_{\mathrm{YP}} \mathrm{Dem}\left[{ }_{\mathrm{YP}} \mathrm{Y}\left[{ }_{\mathrm{wP}} \mathrm{Num}\left[{ }_{\mathrm{wP}} \mathrm{W}{ }_{\mathrm{ZP}} \mathrm{A}\left[{ }_{\mathrm{ZP}} \mathrm{Z}\left[{ }_{\mathrm{NP}} \mathrm{N}\right]\right]\right]\right]\right]\right]\right]\right]$

If there is no movement, then the surface order will be exactly the same as the underlying universal order, namely Dem-Num-A-N. If the NP moves one notch up around A (into [Spec, ZP]), then the ordering will be Dem-Num-N-A. With the NP moving two notches around Num and A (into [Spec, WP]), then Dem-N-Num-A is what will be produced. If the NP moves all the way up (into [Spec, YP]) within the DP, the ordering of N-Dem-Num-A will be the outcome. Alternatively, the NP can move "successively to each [...] Spec[,...] pied-piping the category that dominates it, in a 'roll-up' fashion" (Cinque, 2005:317). Thus once the NP has moved one notch up around A, the resulting category (consisting of $\mathrm{N}-\mathrm{A}$ in that order) can further move one notch up around Num, giving rise to the order Dem-N-A-Num. Moreover, the resulting category (consisting of N-A-Num) can in turn move one notch up around Dem, producing the mirror-image of the universal DP order, i.e. N-A-Num-Dem. In contrast, the unattested orderings such as Num-Dem-A-N and Num-Dem-N-A are not able to be derived from the universal DP-internal order in (5). For example, Num-Dem-A-N would involve no movement of the NP around A, but the remaining ordering of Num-Dem violates the relevant part of the universal order in (5). In the case of Num-Dem-N-A, there can be two possible explanations. First, if the NP has moved around A, then the left-hand part of the ordering, i.e. Num-Dem, does not conform to the universal order in (5). Second, if the NP has moved with the pied-piping of the category that dominates it (i.e. either [Dem-N] or [Num-Dem-N]), the original order would have been Num-A-[Dem-N] or A-[Num-Dem-N]. Neither of these two, however, would conform to the universal DP-internal order in (5). From this reasoning, Cinque (2005:324-5) draws the conclusion that it is the movement of the NP or an XP dominating it that is responsible for engendering the cross-linguistic variation on the universal word order in (5) (precisely, Kayne's universal Spec-H-Compl order, which (5) is reduced ultimately to).

Working out the 'mechanics' of deriving the complete range of surface word order variants from the underlying Spec-H-Compl order is a central issue in MP, which focuses on discovering interface conditions for the performance systems. Thus the data and generalizations from large-sample-based typological research will play a vital role in addressing this central issue, as foreshadowed by Cinque's work. Without an understanding 


\section{Jae Jung Song}

of cross-linguistic word order variation in the first place, it is not possible to ascertain what surface variants the underlying universal Spec-H-Compl order undergoes movement operations to convert itself into (and what movement operations result in unattested surface variants). To wit, the relevance of cross-linguistic structural variation to minimalist inquiry is dictated by the need to be able to write specific interface instructions for the performance systems. As has been argued here, this need is inextricably linked to MP's own theoretical position.

\subsection{GG goes functional: performance conditions on linearization}

Before bringing this section to a close, it is worth taking a look at Richards's (2010) minimalist analysis of case marking, which reinforces the relevance of LT to minimalist inquiry and highlights the increasingly blurred distinction in MP between competence and performance. Richards (2010) has proposed interface conditions on linearization or, more accurately, "conditions imposed on the narrow syntax [i.e. the "generative engine" that constructs derivations in phases (Chomsky, 2001:3, 2004:208)] by its interface with phonology" (Richards, 2010:1). The impact on the narrow syntax of phonology, including prosody, is so profound that Richards (2010:205) comes to the view that "the construction of phonological representations begins earlier in the syntactic derivation than was previously thought", i.e. before the syntactic derivation has ended. For instance, when linearizing instructions are generated on the basis of Kayne's (1994) LCA — which Richards assumes - they must further comply with what Richards (2010:5) calls the "Distinctness Condition":

(6) Distinctness Condition

If a linearization statement $\langle\alpha, \alpha\rangle$ is generated, the derivation crashes.

What this interface condition rejects as illicit are those syntactic objects in which two syntactic nodes are of the same type (e.g. V, DP [= NP in earlier GG] or PP). Thus structures with two identical nodes will not be able to be linearized at Spell-Out. For example, consider 'nominalized' phrases, as in:

(7) a. the singing [of the children]

b. the singing [of songs]

c. *the singing [of songs] [of the children]

d. the singing [of songs] [by the children]

The gist of Richards's (2010:9) explanation for the ungrammaticality of 7c, as opposed to the other grammatical nominalized phrases, is that the two PPs, i.e. of songs and of the children, cannot undergo linearization because of the condition in (6), i.e. the two adjacent of-marked DPs violating the Distinctness Condition. In contrast, $7 \mathrm{~d}$ can be linearized precisely because of the use of different prepositions for the two adjacent DPs in the relevant linearization statement, i.e. two different types of PP or <of DP, by DP>. The 
remaining examples, in $7 \mathrm{a}$ and $7 \mathrm{~b}$, also do not incur any Distinctness violation, with the two relevant expressions being of distinct types, i.e. $\langle\mathrm{DP}$, of DP $\rangle$. Other similar examples in which Distinctness violations are avoided by insertion of extra structure include: the destruction of the city vs. *the destruction the city (i.e. $\langle\mathrm{DP}, \mathrm{DP}\rangle$ ), and John was seen to leave vs. *John was seen leave (i.e. $\langle v, v\rangle$ ). Richards (2010:54-127) also adduces many other structural strategies that languages draw upon in order to comply with the Distinctness Condition in (6). One such strategy is none other than case marking of DPs. When the LCA generates a linearization statement of $\langle\mathrm{DP}$, DP $\rangle$ in violation of (6), languages such as German and Japanese "assign different kinds to DPs with different values for case or animacy" (Richards, 2010:141). To wit, the two adjacent DPs are case-marked differently to avoid the Distinctness violation.

This minimalist analysis, advanced by Richards (2010), is as functional as it gets in that it is essentially the explanation proposed in LT under the Discriminatory Theory of case marking (e.g. Comrie, 1978, 1989; Dixon, 1979, 1994; also Næss, 2007). The majority of languages with case marking fall into one of the two types of case marking, i.e. nominative-accusative and ergative-absolutive. Moreover, the nominative case tends to be zero (i.e. a zero morpheme) and the accusative case non-zero, whereas the ergative case tends to be non-zero and the absolutive case zero. These two seemingly disparate typological observations have been explained in the Discriminatory Theory in the following way. The primary function of case marking is to distinguish the transitive subject from the object (both occur in one and the same clause). The reason why zero marking is used for the nominative and absolutive case is that these two cases both involve the intransitive subject. The intransitive subject, however, does not need to be distinguished from other DPs because it is the only (core) DP in a clause. For this reason, it tends to be zero-marked. Now, the intransitive subject aligns itself with the transitive subject in nominative-accusative case marking, while it aligns itself with the object in ergative-absolutive case marking. Hence zero case-marking for the nominative case (i.e. transitive and intransitive subject) and absolutive case (i.e. intransitive subject and object) as a whole. The point of this typological discussion is that Richards's (2010) Distinctness Condition is essentially identical to what the Discriminatory Theory has said about the functional basis of case marking. This should not come as a surprise because interface conditions, by definition, are bound to have much more to do with performance than with competence. The need to keep two adjacent syntactic nodes of the same type (e.g. DP) distinct from each other, as captured by Richards's Distinctness Condition in (6), is fundamentally perception-based or ultimately, performance-driven.

\section{Conclusion}




\section{Jae Jung Song}

Within minimalist GG, an increasing amount of attention will be paid to the 'discovery' of interface conditions. Interface conditions have more to do with performance than with competence. So much so that, as already mentioned, one of the leading MP theorists avers:

[t]his [i.e. the decreasing gap between competence and performance] has a repercussion for competence. It provides a rationale for the existence of agreement [between competence and performance]" (Uriagereka, 1999:276).

This is indeed a striking position statement, given GG's opposition, since its inception, to the inclusion of performance in linguistic theory. When interface conditions are pursued in earnest, there is no escaping what may be characterized as functional motivations or explanations, as can be seen from \$2.4. This inevitability, if it can be called that, is not unlikely to become something of a watershed in the history of GG, because functional motivations or explanations have previously been generally ignored or shunned, if not scoffed at, by generative grammarians. Equally importantly, interface conditions have no option but to make reference to, or make use of, such typological data and generalizations as uncovered by LT, because various abstract structures, predominantly favored by minimalist GG, must eventually be reconciled with rich cross-linguistic structural variation by means of interface instructions fully legible to the performance systems, e.g. the sensorimotor system (read: speech). Thus the relevance of typological diversity to minimalist inquiry is likely to be heightened, not reduced, by MP's internal requirements (see Zwart, 2009 for one MP insider's view of this kind). Siewierska's (2006) foresight of the role of LT in forging a bridge between functionalism and formalism - with an even greater degree of convergence between the two than she envisaged - is well-founded: Linguistic Typology is where functionalism and formalism will probably meet.

\section{References}

Boeckx, C. 2006. Linguistic Minimalism: Origins, Concepts, Methods, and Aims [M]. Oxford: Oxford University Press. 2008. Bare Syntax [M]. Oxford: Oxford University Press.

Chomsky, N. 1965. Aspects of the Theory of Syntax [M]. Cambridge, MA: MIT Press. 1993. A Minimalist Program for Linguistic Theory [A]. In K. Hale and S. J. Keyser, eds., The View from Building 20: Essays in Linguistics in Honor of Sylvain Bromberger [C]. Cambridge, MA: MIT Press, 1-52.

1995a. Bare Phrase Structure [A]. In G. Webelhuth, ed., Government and Binding and the Minimalist Program [C]. Oxford: Blackwell, 385-439. 1995b. The Minimalist Program [M]. Cambridge, MA: MIT Press. 2000. Minimalist Inquiries: The Framework [A]. In R. Martin, D. Michaels and J. Uriagereka, eds., Step by Step [C]. Cambridge, MA: MIT Press, 89-155. 2001. Derivations by Phase [A]. In M. Kenstowicz, ed., Ken Hale: A Life in Language [C]. Cambridge, MA: MIT Press, 1-52.

2004. Beyond Explanatory Adequacy [A]. In A. Belletti, ed., Structure and Beyond: The Cartography of Syntactic Structures [C], vol. 3. Oxford: Oxford University Press, 104-131. 


\section{Relevance of Linguistic Typology to Formal Theory: Minimalist Inquiry and Word Order}

2005. Three Factors in Language Design [J]. Linguistic Inquiry, 36:1-22.

Cinque, G. 1996. The ‘Antisymmetric' Programme: Theoretical and Typological Implications [J]. Journal of Linguistics, 32:447-464.

2000. On Greenberg's Universal 20 and the Semantic DP [J]. University of Venice Working Papers in Linguistics, 10(2):45-61.

2005. Deriving Greenberg's Universal 20 and Its Exceptions [J]. Linguistic Inquiry, 36:315-332.

2010. Deriving Word Order Types: A Change of Perspective [Z]. MS. University of Venice.

Comrie, B. 1978. Ergativity [A]. In W. P. Lehmann, ed., Syntactic Typology: Studies in the Phenomenology of Language [C]. Austin: University of Texas Press, 329-394.

1989. Language Universals and Linguistic Typology [M], 2nd edn. Oxford: Blackwell.

Dixon, R. M. W. 1979. Ergativity [J]. Language, 55:59-138. 1994. Ergativity [M]. Cambridge: Cambridge University Press.

Dryer, M. S. 1992. The Greenbergian Word Order Correlations [J]. Language, 68:81-138. 2005. Order of Subject, Object and Verb [A]. In M. Haspelmath, M. S. Dryer, D. Gil and B. Comrie, eds., The World Atlas of Language Structures [C]. Oxford: Oxford University Press, 330-333.

Epstein, S. D., E. M. Groat, R. Kawashima and H. Kitahara. 1998. A Derivational Approach to Syntactic Relations [M]. Oxford: Oxford University Press.

Greenberg, J. H. 1963. Some Universals of Grammar with Particular Reference to the Order of Meaningful Elements [A]. In J. H. Greenberg, ed., Universals of Language [C]. Cambridge, MA: MIT Press, 58-90.

Hawkins, J. A. 1983. Word Order Universals [M]. New York: Academic Press.

Hornstein, N. 2009. A Theory of Syntax: Minimal Operations and Universal Grammar [M]. Cambridge: Cambridge University Press.

Hornstein, N., J. Nunes and K. K. Grohmann 2005. Understanding Minimalism [M]. Cambridge: Cambridge University Press,

Huang, C.-T. J. 1982. Logical Relations in Chinese and the Theory of Grammar [D], PhD dissertation. Cambridge, MA: MIT.

Kayne, R. S. 1994. The Antisymmetry of Syntax [M]. Cambridge, MA: MIT Press. 2000. Parameters and Universals [M]. Oxford: Oxford University Press.

Marantz, A. 1995. The Minimalist Program [A]. In G. Webelhuth, ed., Government and Binding Theory and the Minimalist Program [C]. Oxford. Blackwell, 349-382.

Næss, A. 2007. Prototypical Transitivity [M]. Amsterdam: John Benjamins.

Polinksy, M. 2011. Linguistic Typology and Formal Grammar [A]. In J. J. Song, ed., The Oxford Handbook of Linguistic Typology, Oxford. Oxford University Press, 650-665.

Richards, N. 2010. Uttering Trees [M]. Cambridge, MA: MIT Press.

Seddy, S and V. Samek-Lodovici 2011. On the Ungrammaticality of Remnant Movement in the Derivation of Greenberg's Universal 20 [J]. Linguistic Inquiry, 42:445-469.

Siewierska, A. 1988. Word Order Rules [M]. London: Croom Helm.

2006. Linguistic Typology: Where Functionalism and Formalism Almost Meet [A]. In A. Duszak and U. Okulska, eds., Bridges and Barriers in Metalinguistic Discourse [C]. Peter Lang, Frankfurt am Main, 57-76.

Song, J. J. 2012. Word Order [M]. Cambridge: Cambridge University Press.

Tomlin, R. 1986. Basic Word Order: Functional Principles [M]. London: Croom Helm.

Uriagereka, J. 1999. Multiple Spell-Out [A]. In S. D. Epstein and N. Hornstein, eds., Working Minimalism [C]. Cambridge, MA: MIT Press, 251-280.

Zwart, J.-W. 2009. Relevance of Typology to Minimalist Inquiry [J]. Lingua, 119:1589-1606. 